\title{
After Justice: \\ On the Conditions of Possibility of Justice in the Present
}

\author{
Hernán López-Garay ${ }^{\mathrm{a}}$, Ricardo Sotaquiráa ${ }^{\mathrm{a}, \mathrm{b}}$
}

In so called "developing countries" justice, or rather the lack of it, has become a dominant theme in the lives of millions of citizens. Both, in national and international arenas, the citizens of these countries have to face situations of brutal violation of human rights, extremely unjust distribution of their nations' wealth, generalized corruption of their leaders and institutions (e.g. the administration of justice, public health care, etc.), unfair trade with the economic powers of the world, etc.

These conditions make one think if perhaps the torch of justice has been extinguished in these nations. But then, how this has come about, i.e., what are the conditions of possibility of such unjust social order? Can we recover the torch of justice? How can we keep its flame alive? Do we need a new social order for this to happen?

In order to tackle these and other related questions, we started a project two years ago, based on the principles and concepts of interpretive systemology (López-Garay, 1986; Fuenmayor, 1991a,b). Our research has been focused on the phenomenon of injustice in Venezuela. Our starting point has been the current social debate to reform justice (both social and penal justice) in Venezuela. In particular, we are investigating what conception of justice is embodied in the reform proposed by the state. We want to find out what is the "order of things" (i.e., the cultural context of meaning) to which such a notion of justice might be paying tribute. The preliminary outcomes of this research have opened the way to the design of a counter reform, based on an entirely different conception of the world. A debate between the two reforms will be conducted and its outcomes will help us not only to gain a holistic understanding of justice, but also to bring forth some of the features of what it looks as the emergence of a new epoch. The paper intends to be an illustration of a new systemic way of "managing" complex social issues, a way that is in contrast with some current practices in management and systems sciences.

\section{INJUSTICE: ANOTHER SYMPTOM OF THE MALAISE OF MODERNITY?}

According to Charles Taylor (1991) there is an increasing feeling in Western Civilization that modernity has gone astray. The project of the Enlightenment,

\footnotetext{
a Departamento de Sistemología Interpretativa, Universidad de los Andes, Mérida 5101, Venezuela.

${ }^{\mathrm{b}}$ Facultad de Ingeniería de Sistemas, Universidad Autónoma de Bucaramanga, Bucaramanga, Colombia.
} 
whereby reason would liberate man from the oppression of nature and cultural forces, seems to have failed. What are the symptoms of this failure? One of them is concerned with lack of holistic meaning; another has to do with local and global orders perceived as unjust. The latter is acutely manifest mainly in so called underdeveloped societies. The former is present mainly in developed ones. Perhaps the two are interrelated and have to do with the sense of a lost of justice. The case is that for underdeveloped societies the malaise of modernity seems to manifest itself more in a strong concern with a lack of justice than with a lack of sense in life: people in those countries claim everyday for a just social order (i.e., a claim to the right to education, health care, work, respect to their human dignity, equal sharing of common resources, etc.). Thus, living in these countries and being aware of these issues create the proper conditions to question the social order and wonder where has justice gone.

Following we are going to present some preliminary results of our project, but first we will summarize the main systems ideas which are guiding the inquiry.

\section{SYSTEMS THINKING REVISITED}

How does a systems thinker approach the study of any complex phenomena? A systems thinker is someone that has made the commitment to see the world from a holistic perspective. So, what does it mean to take a holistic view of, say, justice? For Interpretive Systemology it means to unfold the holistic meaning of that which has been "distinguished" as the research object. As we will explain in a moment, this view assumes an antireductionistic posture: "things" are never standing by themselves, rather they are like "holograms" i.e., things make their presence always within a rich web of cultural and historical practices, or "forms of life", that constitute their very essence (like the rays of a hologram constitute the object which, an innocent bystander might take as standing by itself). In other words, the "essence" of the object is neither within nor without. The two form a unity.

In showing up, in "appearing" a thing, it actually co-discloses the "web" of "rays" or the "background" which constitutes it and sustain it, thus keeping what shows up from "falling", "sinking" or dis-appearing. The co-disclosure of the background can be illustrated by the act of drawing a circumference. In such an act not only a circle is "created" (distinguished) but also its background (i.e., what is outside the circle). Thus, we can say that any phenomenon is a figure-background distinction (distinction both as a verb and a noun). In these terms, a system is a figure-background unity. A holistic approach, then, focus its efforts on the problem of understanding the figure-background nature of any phenomenon.

Three comments must be made at this point. First, notice that systems are neither a set of interrelated elements, nor their unity can be thought as the emergent property of its parts. Second, the system's environment is neither a set of elements, nor is something which influences the state of the system. The reader more familiar with classical notions of systems might think the notion of "background" is 
equivalent to that of "system's environment". We must warn him/her, that for reasons that follow ${ }^{1}$, "background" is not concept translatable into the mechanistic or the organismic paradigm of systems. In fact, and this is our third comment, the background has a peculiar nature. In López-Garay \& Suárez (1998), is explained that the background is an indistinct and homogeneous "outside" (e.g., the circle's outside in our example of the act of drawing a circle), not something made of elements. It is also elusive, i.e., each time we want to explore what it is, we are forced to draw distinctions, thus creating new figure-background units and therefore, dissolving the original background. Another characteristic is its flux-like nature. This is because every act of distinction is an occurrence, and occurrence implies change (otherwise it would not be possible to identify it as something happening). This means that systems are not static but continuously in the process of becoming, which in turn means that their occurrence is a continuously coming from a past which is actualized in the present. Consequently, systems are historical ${ }^{2}$.

Another important characteristic of the background is this. In every specific situation where a distinction is made (e.g., a system's boundary is drawn), the background brought together to light with the distinction seems to be a background of familiarity and concern. Hall (1993, p.132), making reference to Heidegger's work express it thus: "...things show up for us or are encountered as what they are only against a background of familiarity, competence, and concern that carves out a system of related roles into which things fit."

What is the nature of this implicit background by means of which things are intelligible or meaningful, and which we seem to be unaware of? Taylor (1997, p.69) points out that we are not simply unaware of it, in the same sense that one can be unaware of what is happening in the moon right now, simply because the background makes intelligible what one is aware of in a given moment. Hence, it is inextricably related to what is the focal object at a given moment. Furthermore, this background, can be articulated i.e., I can bring it out "...of the condition of implicit, unsaid contextual facilitator... In this activity of articulating, I trade on my familiarity with this background."

The picture one gets from these descriptions is that things always show up associated with an implicit web of practices "...Take a humble entity like a jug. As it shows up in the world of the peasant, still unmobilized by modern technology, it is redolent of the human activities in which it plays a part, of the pouring of wine at the common table, for instance. The jug is a point at which this rich web of practices can be sensed, made visible in the very shape of the jug and its handle, which offers

\footnotetext{
${ }^{1}$ Cooper (1990) has also extensively argued about the nature of the background (boundary drawing) and its importance for the study of human organizations. Churchman (1968), Checkland (1981), Flood \&Ulrich (1990), have identified similar notions (but not the same) to that of "background". Their notions of Weltanschauung and constitutive meanings, have played an important role in the development of systems thinking.

${ }^{2}$ About the historical constitution of phenomena see for instance, Fuenmayor (1991a,b); López-Garay (1986, ch.7).
} 
itself for this use." (Taylor, 1997, p. 122, italics added). Hence, what is essential to the jug, its use and form, is shaped by the rich set of practices of the peasants. Certainly, these peasants are not fully aware of this "socio-historical" background each time they pour a glass of wine from the jug, yet they are neither completely unaware of this.

We can now summarize several characteristics of the background with the following quote from Taylor (1997): the jug as such "...stands on and emerges out of a vast domain of still unformed and unidentified reality. This is a field of potential future forming, but it is limitless, inexhaustible. All forming is surrounded by and draws on this unformed. If we are not closed to it, the jug will also speak of its history as a formed entity, of its emergence from unformed matter, of its continuing dependency on the unformed, since it can only exist as an entity as long as it is supported by the whole surrounding reality." (p.122, italics added).

The above implies that the primary task of a systems approach is to display, or reveal how the figure is constituted by its "background", and vice versa. As we will explain in a moment, this task consists in the "opening" or disclosing of the background, i.e., unfolding its historical interpretive nature. It is interpretive because, every attempt at opening it, demands building a context of meaning, in order to see how the figure "fits" such a context. But given that people have different "backgrounds" (in the everyday use of this word), different contexts of meaning can be designed for a given figure. In other words, we can build different interpretations (i.e., different ways of displaying how the figure "fits" its background). Its sense as a whole (its holistic sense) is the unity underlying these different interpretations.

\section{AN INTERPRETIVE SYSTEMIC STUDY OF JUSTICE: SOME PRELIMINARY RESULTS}

Based on the previous framework, we are conducting a systemic research on justice in Venezuela. Accordingly, we have initially "distinguished" such a complex socio-historical phenomena named justice as "an unjust social order". Following, we are going to explain how to disclose the "background" of such a distinction. We will keep in mind that such disclosings are aimed at helping to explore three basic questions guiding our research, namely: has the torch of justice been extinguished? Can we recover it? How can we keep its flame alive?

\subsection{A "Narrow" Opening of the "Background": Logic-Based Contexts}

Our first attempt to disclose the background of the phenomenon "unjust social order" demanded questions such as: what is considered a "just social order"? What is the notion of "justice" underlying this accusation? To pursue these questions, we began to build what we call a logic-based interpretive context. This context has the form of a "theory", with a central concept, say justice, being developed in rational 
conceptual system bounded together exclusively by logical relationships ${ }^{3}$. In this connection we have sought inspiration in Rawl's (1971) theory of justice and in MacIntyre's (1988) theory of liberal justice. We have chosen the former because it is a good example of what we call here a logic-based context. The latter puts in historical perspective the former and show the vital importance of doing so in order to understand the modern notion of justice. Our initial attempts to interpret our current social order in this liberal context of meaning have resulted in two important outcomes. The first outcome is that the logic-based context has been questioned by the "background" itself for not taking into account the fact that its notion of justice is historically and culturally bonded. For one thing, liberalism did not fall from Mars. From the present cultural context of Western societies, liberalism is the outcome of the project of modernity. The second outcome is, as we might expect (based on the conceptual framework presented in previous sections), a demand from the background for something more specific to the particular phenomenon we are studying, namely, Venezuelan unjust social order. This does not mean that logicbased contexts are not useful as a first disclosing of the background. The point to keep in mind is that the process of disclosing demands what is needed, and we are not supposed to interfere with any methodological precepts such a process. This last comment may be considered a third outcome of the research, namely, the object of research is constituted by the research and vice versa, something absurd from the point of view of classical scientific research (López-Garay, 1998).

\subsection{A "Wide" Opening of the "Background": Historical-Ontological Contexts}

These two outcomes coincide with outcomes from other interpretive systemic studies on public institutions in Latin America (see special issue of Systemic Practice and Action Research, December 1998). They reveal that in order to understand our complex social phenomena, first we need to understand the history of those cultural contexts of meaning that have led us to want to become "moderns" (e.g., wanting to implant Western institutions, such as (Western) justice, universities, democracy, etc.). Certainly, this history cannot be independent from the history of the cultural contexts of meaning that led the Western civilization to "invent" modernity as such.

In other words, to answer the question has the torch of justice been extinguished? we need to perform two fundamental tasks. One is to build the history (a narrative) of the transformations of the cultural contexts, what is called an historical-ontological interpretive context (Fuenmayor \& Fuenmayor, 1998). The notion of history embodied in the historical-ontological concept is explained thus: "The historical question is not then simply: 'Which events have led us to the present?', but 'What has been the series of cultural contexts.... that have led us to

\footnotetext{
${ }^{3}$ Certainly, the idea of logic is based on a cultural background. Within the systems movement, the assumed purity of logical relationships in the construction of theories and conceptual models is questioned by Checkland \& Tsouvalis (1996).
} 
experience reality (including history) in the way we do at present?"' (ibid., italics added). One very important aspect of this history is how we have come to appreciate the world as "moderns" of a particular kind, namely, as people tutored by the real modern ones (i.e., the Western cultures)! The second task is to ask persistently to this historical interpretive context the question about the sense of justice in the present (in Venezuela). Notice this second task is quite different from one pursuing the following questions: why have the institutions of modernity failed in Venezuela (among then the institution of justice) and what can we do to make them work properly? A research led by these questions would probably aimed at finding a causal theory of the failure of liberalism in Venezuela. Once such a theory is built, actions to correct the situation would be taken. As the reader might have noticed it, our research goes in a radically different direction. For instance, we want to show, not only that we have not managed to copy the Western system of justice in Venezuela, but also, and more important, to provide a context that explains why such a "failure" is an actual "success"! Furthermore, we want to go further and argue, from the historical-ontological context, that justice itself has died!

Although we have not completed these tasks, already we are handling a hypothesis related to our second research question, namely: can we recover the torch of justice? Again, notice this is a question we are posing to the historicalontological context, not to a logic-based context. Our hypothesis is that at a time of fragmentation and the lost for a will to holistic sense (López-Garay 1994; Fuenmayor, 1997), the light of justice has to died out. Therefore, there seems to be the need for a preliminary task, namely, to recuperate the will for holistic sense. How can our project help in this direction is, at this point of the research, not clear yet $^{4}$. What it is clear is the following. Assuming the conditions for the recovery of the torch of justice are given (these conditions are implicit in the historicalontological context), an important task is to design a reform that can keep the flame of justice alive. The design of a justice reform will be advanced in the light of the historical-ontological context. Inasmuch as such a context is neither fully developed nor understood, the design will help to unfolded and enrich it. The starting point of this recursive process will be the current debate on justice animated by the desired of the Venezuelan state to carry out the project of building a more just society. Two poles around this debate are: neoliberals and globalizers, on one side, and those who attack the neoliberal project on the other side. We will enter this debate with a counter reform. Notice that our design is not merely a "blue print" for a new social order, where the torch of justice will light again. It is, fundamentally, a device to help us obtain a more profound understanding of the present. Let us explain this point in the final section of this paper.

\footnotetext{
${ }^{4}$ In our Department, the project: Education for the Twentieth First Century, led by professor Fuenmayor is precisely aiming at helping our culture to recover this will.
} 


\section{MANAGEMENT AS THE SCIENCE OF MEANING-FULL DECISIONS}

We would like to conclude drawing some quick comparisons between the systemic approach to "manage" complex social phenomena presented in this paper and more conventional approaches of management and systems sciences. The comparison suggests that management science, at least in relation to its application to manage complex social systems, may have to follow a different road, one related to meaning-full decisions rather than merely effective and efficient decisions.

Some streams of management and systems sciences (Flood, 1998), embody a view of the manager as a hard-headed practical pragmatic realist. Accordingly, the realm of managerial expertise is defined as one purport to be objectively grounded, a realm whose aim is to provide solid knowledge to predict and control human organizations. Success in this realm is based on scientific knowledge (i.e., a sound stock of law-like generalizations). A scientific manager is then a man that uses the knowledge of management science to organize and control some course of events (MacIntyre, 1985, p.101). Planning, and design are some of the tools provided by management science to achieve these purposes.

But the interpretive systemic perspective provides a different possibility. As we have seen, according to this perspective human action is always embedded in a cultural web which constitute action, man, and phenomena in general. Therefore, we can say that, from this perspective, humans are always engaged beings (Taylor, 1997, ch.4). Moreover, we are engaged not only to our cultural contexts but also to the sediment of their gradual transformations. Inasmuch as these transformations are not of our own making (i.e., we do not decide we are going to see the world in "modern" or "postmodern" terms), we can hardly talk about controlling our lives at will. In fact, since we are historical and culturally engaged beings this means that we can never find a sort of neutral, a-historical ground from which we can see the world and "control" it. On the contrary, since we are always constituted by a cultural background, then we might be more truthful to our human condition if we say that it is the latter that actually controls us! In another context, Flood (1998) quoting Peter Reason has made a similar point: "phenomena as wholes can never be fully known for the very reason that we are part of them, leading us to acknowledge and respect the great mystery that envelops our knowledge" (p.95). But if this notion of man and reality were seriously taken then what would be the sense of a science of management, which by definition is the science of control (Beer, 1959)?

Churchman, a management scientist that has made important contributions to the systems movement, could perhaps be interpreted in the direction offered by our interpretive systemic perspective. In his well known book The Systems Approach, he says that this approach is in the business of deceptions, by which he means that every time we think we have caught reality in our perspectives, we learn, more to our dismay, that they are too limited. (Churchman, 1968, pp.228-230). According to this view, management science is then in the business of liberation, that is, it is in the business of helping us to get rid of the illusion that science (or any other 
perspective) has access to special knowledge that can be used to predict and control social phenomena.

The interpretive systemic view opens the door, then, to a completely different way of dealing with social phenomena, a way based on appreciation of the mystery of being, its multiple manifestations and our finitude. In its light the task of management science could become, then, one of helping to make meaning-full decisions, i.e., decisions based on some degree of holistic appreciation of that background which constitute us and our actions. Clearly, many of its concepts would have to change. Take for instance one of them, the concept of design. In the new perspective design would not be merely a tool to find the most appropriate means to achieve some given objective. Rather, it could be the means to reveal our constitutive engagement and, consequently, that of social phenomena in general. This is, precisely, the use we intend for design in our project.

\section{REFERENCES}

Beer, S., 1959, "Cybernetics and Management", The English Univ. Press, London.

Cooper, R., 1990, Organization/disorganization, in: "Theory and Philosophy of organizations", J.Hassard y D.Pynn, eds., Routledge, UK.

Checkland, P. B., 1981, "Systems Thinking, Systems Practice", Wiley, Chichester.

Checkland, P. B. and Tsouvalis, C., 1996, Reflecting on SSM: The link between root definitions and conceptual models, in: The Lincoln School of Management Working Paper Series, 5, University of Lincolnshire \& Humberside, Lincoln, UK.

Churchman, C. W., 1968, “The Systems Approach”, Dell, New York.

Flood, R., 1998, Action research and the management and systems sciences, Systemic Practice and Action Research, 18:1.

Flood, R., Ulrich, W., 1990, Testament to conversations on critical systems thinking between two systems practitioners, Systems Practice, 3: 1.

Fuenmayor, R., 1991a, The self-referential structure of an everyday-living situation: A phenomenological ontology for interpretive systemology, Systems Practice, 4: 449472.

Fuenmayor, R., 1991b, Truth and openness: An epistemology for interpretive systemology, Systems Practice, 4: 473-490.

Fuenmayor, R., 1997, The historical meaning of present systems thinking, Syst. Res. Behav. Sci., 14:4.

Fuenmayor, A. and Fuenmayor, R., 1998, Researching-acting-reflecting on public health services in Venezuela: II. Community action and critique, Systemic Practice and Action Research, 18:6.

Hall, H., 1993, Intentionality and world: Division I of Being and Time, in: "The Cambridge Companion to Heidegger", C. Guignon, ed., Cambridge University Press, Cambridge.

López-Garay, H., 1986, “A Holistic Interpretive Concept of Systems Design”, Ph.D. dissertation, University of Pennsylvania, The Wharton School, Philadelphia.

López-Garay, H., 1994, Proyecto de una plataforma de base para pensar sistémicamente el problema del desarrollo de América Latina, Sistémica 94, Instituto Andino de Sistemas, Lima, Perú. 
López-Garay, H., 1998, Interpretive systemology and systemic practice, guest editorial, Systemic Practice and Action Research, 18:6.

López-Garay, H., and Suárez, T., 1998, The holistic sense of prison phenomena in Venezuela: III. The unity of the research, Systemic Practice and Action Research, 18:6.

MacIntyre, A., 1985, “After Virtue: A Study in Moral Theory”, Duckworth, London.

MacIntyre, A., 1988, "Whose Justice? Which Rationality?", University of Notre Dame Press, Notredame, Indiana, USA.

Rawls, J., 1971, “A Theory of Justice”, Oxford.

Taylor, C., 1991, “The Malaise of Modernity”, Canadian Broadcasting Corporation, Canada.

Taylor, C., 1997, Heidegger, language and ecology, in: "Philosophical Arguments", Harvard University Press, Cambridge. 